\title{
NATURAL HISTORY NOTE \\ First records of wing defects in phyllostomid bats from Colombia
}

\author{
Dennis Castillo-Figueroa ${ }^{1, *}$, Jairo Pérez-Torres ${ }^{1}$
}

\author{
${ }^{1}$ Pontificia Universidad Javeriana, Unidad \\ de Ecología y Sistemática (UNESIS), \\ Departamento de Biología, Laboratorio \\ de Ecología Funcional, Bogotá, Colombia. \\ *Corresponding author: \\ dennis.castillof@gmail.com \\ DOI: https://doi.org/10.14709/ \\ BarbJ.11.1.2018.01
}

Keywords: Abnormalities, Anomalies, Chiroptera, Collection specimens, Wing damage, Wing injuries.

received: December, 2nd 2017 accepted: April, 24th 2018

\begin{abstract}
Bat wings are modified forelimbs with a skin membrane that is stretched between elongated digits. The digits are composed of two structures: metacarpals and phalanges. Osteological, tail, chromatic and dental anomalies have been documented for bats, but there have been very few records of wing defects such as anomalies of the phalanges and metacarpals. In this note, we report nine cases of wing defects in Colombian bats. All belonged to the family Phyllostomidae, representing four subfamilies, six genera, and seven species (Sturnira lilium, Sturnira bogotensis, Artibeus planirostris, Uroderma bilobatum, Carollia perspicillata, Desmodus rotundus, Glossophaga soricina). Specifically, three types of wing defects were identified: accessory cartilage, broken digits and nonsymmetrical digits. The possible impacts of wing defects on flight behavior and ecology of bats are discussed. Additional data is needed to evaluate the frequency of each type of wing defect in bat populations.
\end{abstract}

The development of wings is a key innovation that enabled the broad radiation of bats (Cooper \& Sears 2013). Bats achieved the capacity for powered flight, leading to the colonization of different ecological niches during their evolutionary history (Sears et al. 2006). Bat wings are special modifications of forelimbs, in which the skin membrane (dactylopatagium) is stretched between elongated digits (digits II-V) (Wang et al. 2010). The digits are comprised of two main structures: metacarpals and phalanges. These structures show a gradient of reduced mineralization from the base of metacarpals to the tip of phalanges, minimizing the density of the bone towards the wing tip, and making the phalanges more flexible and aerodynamic (Norberg 1972, Papadimitriou et al. 1996, Swartz \& Middleton 2008 ).

Bats present numerous morphological anomalies: osteological (Kunz \& Chase 1982), tail (Mitchell \& Smith 1966), chromatic (Lucati \& López-Baucells 2017, Caire \& Thies 1988) or dental anomalies (Phillips \& Jones 1970, Ramírez-Pulido \& Müdespacher 1987, López-Aguirre 2014, Esquivel-Melo et al. 2017). For instance, the rarity of the polydactyly anomaly in bats has been well-documented in species such as Pipistrellus subflavus (Jennings 1958), Myotis velifer (Caire \& Thies 1988, Pekins 2009), and Tadarida mexicana (Koford \& Krutzsch 1948). Regarding wings, ruptures of wing membranes (Voigt 2013), bone abnormalities (Davis 1968), and additional cartilages (Törne 1913) have already been reported. Nevertheless, wing defects are still poorly documented in bats, unlike other anomalies such as those mentioned above. Due to their key roles in flight performance, specific anomalies related to the structure of phalanges and metacarpals represent a key evolutionary process on bat behavior and evolution.

Wing defects can be injuries caused during the life of the bat because of infections, attacks of predators, collision with objects, among others (e.g. membrane holes, missing membrane parts, embedded thorns and cactus spines), but also anomalies seemingly due to development (e.g. bone abnormalities) (Davis 1968). Törne (1913) and Davis (1968) described three types of wing defects, including accessory cartilage, broken digit, and nonsymmetrical digit. Accessory cartilage is an additional structure that arise in some region of the dactylopatagium, usually in the distal region of the digit V (Törne 1913). This cartilage does not connect with any bone element (i.e. metacarpals and phalanges) and has a high degree of independence (Törne 1913). Broken digits are characterized by a reddened swelling at the site of the digit injury. These breaks occurred in the phalanges and metacarpals, frequently in digit III, but also on digits II-V (Davis 1968). Nonsymmetrical digit, as in the nonsymmetrical forearms (Davis 1968), is a striking difference between right and left side of phalanges or metacarpals.

Here, we report for the first time nine cases of wing defects in Colombian bats. We discuss the possible impacts of wing defects on flight behavior and ecology of bats. We reviewed 1555 bat vouchers from the Mammalian Collection at the Museo Javeriano de Historia Natural of Pontificia Universidad Javeriana (MPUJ-MAMM) (Bogotá, Colombia). All the specimens were dead and preserved. The bats reviewed belong to the following families: Emballonuridae, 
Normal wing Wing defect

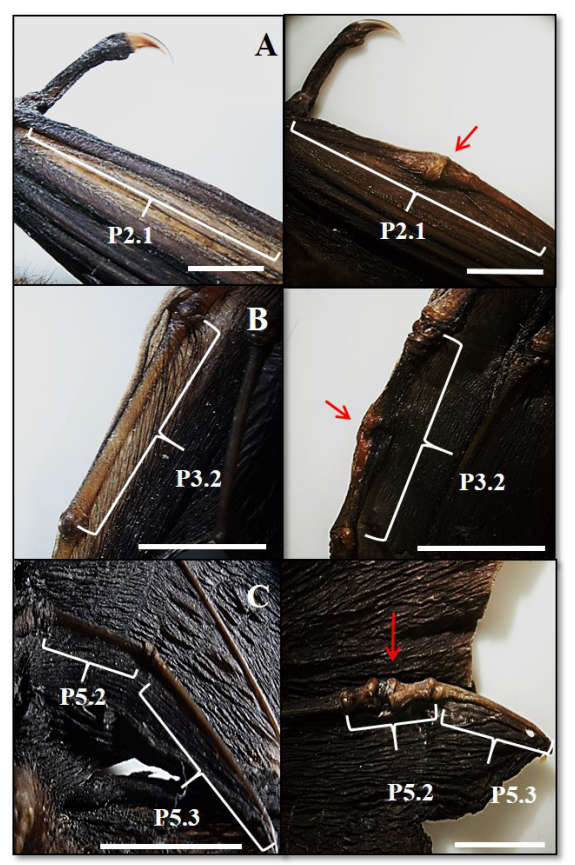

Normal wing
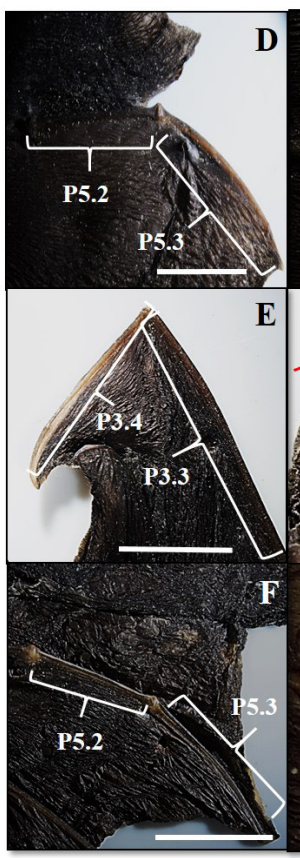

(1)
Wing defect
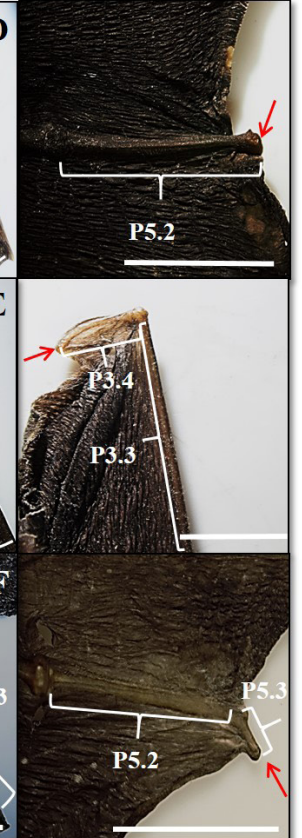

Normal wing

Wing defect

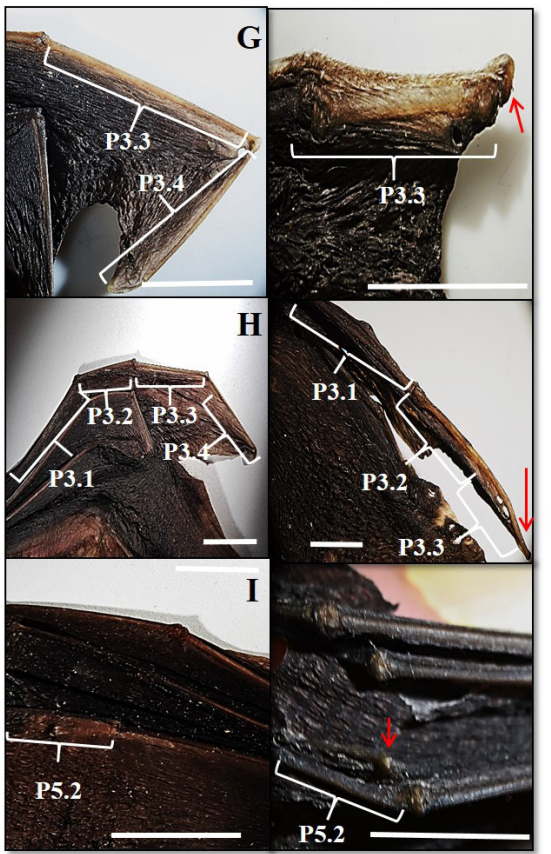

Fig. 1 - Wing defects found in bat specimens. Broken digits in S. bogotensis (A), A. planirostris (B), S. lilium (C). Nonsymmetrical digits in C. perspicillata (D, E, H), U. bilobatum (F), D. rotundus (G). Accessory cartilage in G. soricina (I). Wing structure nomenclature as follows: P2.1: second digit, metacarpal. P3.1: third digit, metacarpal. P3.2: third digit, first phalanx. P3.3: third digit, second phalanx. P3.4: third digit, third phalanx. P5.2: fifth digit, first phalanx. P5.3: fifth digit, second phalanx. Scale bars $=10 \mathrm{~mm}$.

Molossidae, Mormoopidae, Natalidae, Noctilionidae, Phyllostomidae, Thyropteridae and Vespertilionidae; and correspond to 45 genera and 99 species. Metacarpals and phalanges of each digit were assessed in both right and left wings of all the bat specimens. In doing so, we discovered that some bat specimens presented wing defects. Data of the specimen code (MPUJ-MAMM), sex, locality, land use, body size, and date, were taken from the tags of each bat specimen (Table 1).

Nine individuals from 1555 examined (0.6\%), presented wing defects (Table 1). Three had broken digits (Fig.1A, B, C), five had nonsymmetrical digits (Fig. 1D, E, F, G, H), and one presented accessory cartilage (Fig. 1I). All specimens belong to the family Phyllostomidae, representing four subfamilies, six genera and seven species (Table 1). One of the individuals was female and eight were males. The main ecosystem to which the specimens could be assigned was tropical dry forest, and the main land use was cattle ranch. The individuals were from six departments of Colombia (Table 1). For nonsymmetrical digits, important differences between right and left digits were detected. In two cases the structures were absent in some of the sides (Table 2 ).

To the best of our knowledge, this is the first report of wing defects in phyllostomid bats. Previously, bone abnormalities such as nonsymmetrical forearms, curved forearms and fingers, protruding bones, and broken fingers had been reported such as in Pallid bats (Antrozous pallidus) (Davis 1968), as well as accessory cartilage in the tip of the digit $\mathrm{V}$ in other species of vespertilionid bats (Törne 1913). In this note, all the records were from phyllostomid bats. Since $89.51 \%$ of the bat specimens from the MPUJ-MAMM belongs to this family, the probability to detect wing defects in phyllostomid bats was higher than the other families.
Since flight performance depends on wing structure (Norberg and Rayner 1987), wing defects such as broken digits and nonsymmetrical digits could be considered as a possible disadvantage for bat's survival. This is especially true given the functional importance of phalanges and metacarpals. For example, terminal phalanx length improves maneuverability and allows for greater propulsion (Findley et al. 1972), facilitating the capability to rapidly initiate rolls while turning during the flight (Altringham 1996). Metacarpals are important in greater lift-generating abilities (Findley et al. 1972), which is fundamental in carrying large fruits, preys, and fetus in the case of pregnant females.

On the other hand, additional structures (e.g. supernumerary toes) are not expected to affect the fitness (Kunz \& Chase 1982). In the case of digits, the additional cartilage likely does not seem to adversely affect bat survival; indeed, this additional structure could even have some advantage in flight performance. According to Törne (1913), the accessory cartilage could be favorable during the flight because of its autonomy in the mobility, which is certainly greater than the tip of the phalanges. The movements of the additional cartilage could be done in a different direction than the movements of the phalanges, improving the control during the flight (Törne 1913). Thus, the three types of wing defects presented here could be considered to parse out the relation between morphology, flight capacity (maneuverability and energy waste) and the fitness (success in foraging and reproduction) in further studies.

We encourage researchers to report the incidence of wing defects within bat populations. Additional data about the frequency of each type of wing defect in bat populations would be welcome. 


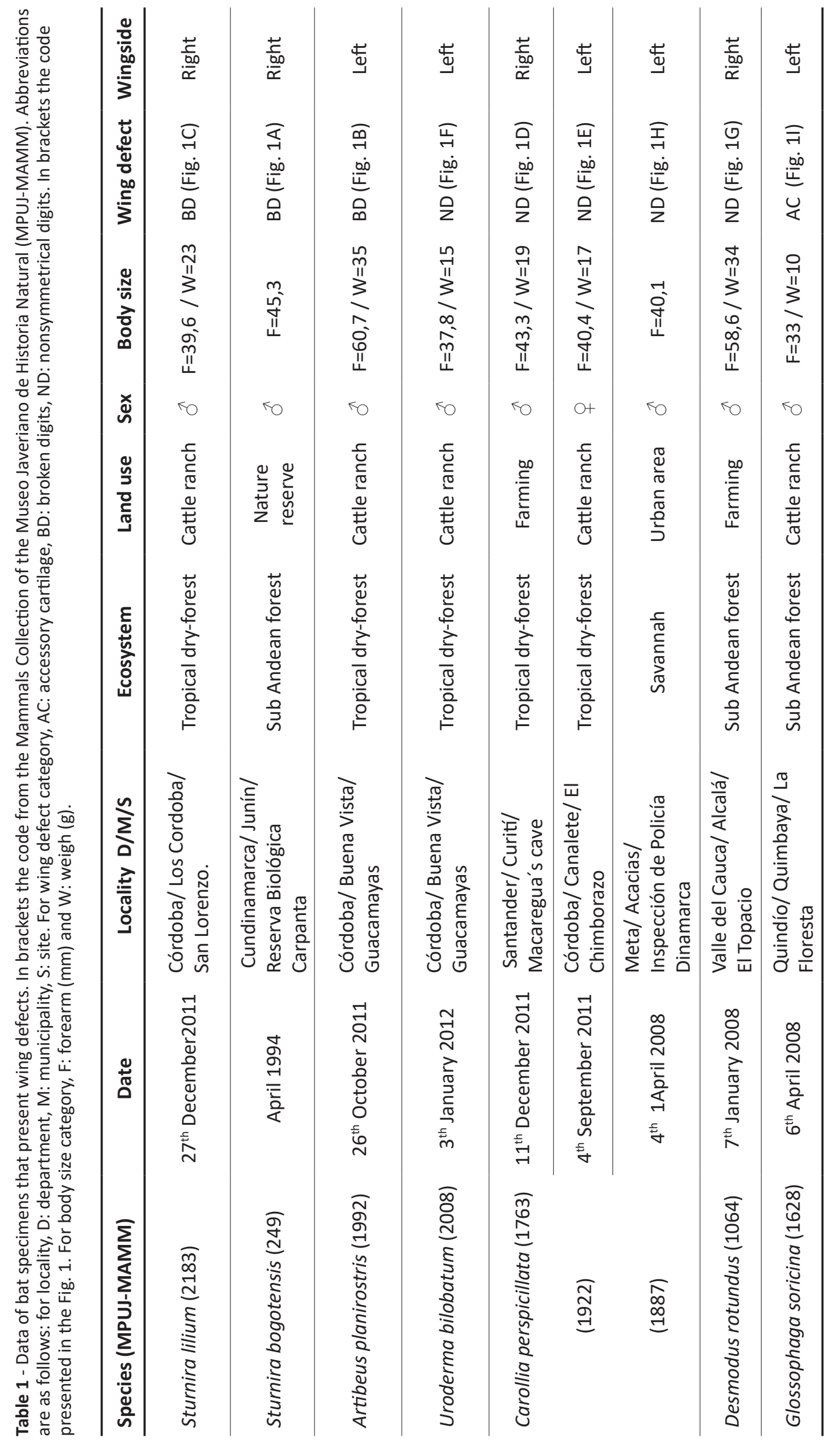


Table 2 - Data of bat specimens that present nonsymmetrical digits. In brackets the code from the Mammals Collection of the Museo Javeriano de Historia Natural (MPUJ-MAMM). Abbreviations are as follows: P3.4: third digit, third phalanx. P5.3: fifth digit, second phalanx.

\begin{tabular}{ccccc}
\hline Species (MPUJ-MAMM) & Wing trait & Right side & Left side & Difference \\
\hline Uroderma bilobatum (2008) & P5.3 & 11,69 & 2,61 & 9,08 \\
\hline Carollia perspicillata (1763) & P5.3 & Absent & 12,04 & 12,04 \\
\cline { 2 - 5 }$(1922)$ & P3.4 & 13,38 & 3,28 & 10,1 \\
\cline { 2 - 5 }$(1887)$ & P3.4 & 13,53 & Absent & 13,53 \\
\hline Desmodus rotundus (1064) & P3.4 & Absent & 14,34 & 14,34 \\
\hline
\end{tabular}

\section{ACKNOWLEDGEMENTS}

Special thanks to Laura L. Garzón-Salamanca for helping to take, edit, and improve the pictures. Erin Bohlender, Tain Velasco-Luquez and Maria Alejandra Cely-Gómez reviewed the English version of the manuscript. The three anonymous reviewers substantially improved the manuscript.

\section{REFERENCES}

ALTRINGHAM, J.D. (1996). Bats: biology and behavior. Journal of Mammalogy 78(3): 986-987. https://doi. org/10.2307/1382962

CAIRE, W. \& THIES, M. (1988). Notes on the Occurrence of Morphological and Color Aberrations in Bats From Oklahoma, Missouri, and Mexico. Proceedings of the Oklahoma academy of science 68: 75-76.

COOPER, L. \& SEARS, K. (2013). How to grow a bat wing. In: Bat Evolution, Ecology, and Conservation. Springer-Verlag, New York, USA. 547 pp. https://doi.org/10.1007/978-14614-7397-8

DAVIS, R. (1968). Wing Defects in a Population of Pallid Bats. The American Midland Naturalist 79(2): 388-395. https://doi.org/10.2307/2423184

ESQUIVEL-MELO, D., CAMELO-PINZÓN, D. \& RODRÍGUEZBOLAÑOS, A. (2017). New record of bilateral hyperdontia in Carollia brevicauda (Chiroptera: Phyllostomidae). Therya 8(1): 71-73. https://doi.org/10.12933/ therya-17-440

FINDLEY, J.S., STUDIER, E.H. \& WILSON, D.E. (1972). Morphologic properties of bat wings. Journal of Mammalogy 53(3): 429-444. https://doi. org/10.2307/1379035

JENNINGS, W.L. (1958). Polydactyly in the Eastern Pipistrel. Journal of Mammalogy 39(3): 437-438. https://doi. org/10.2307/1376160

KOFORD, C.B. \& KRUTZSCH, P.H. (1948). Polydactyly in the Mexican Free-Tailed Bat. Journal of Mammalogy 29(4): 418. https://doi.org/10.1093/jmammal/29.4.418
KUNZ, T.H. \& CHASE, J. (1983). Osteological and ocular anomalies in juvenile big brown bats (Eptesicus fuscus). Canadian Journal of Zoology 61(2): 365-369. https://doi. org/10.1139/z83-048

LÓPEZ-AGUIRRE, C. (2014). Dental anomalies: new cases of Artibeus lituratus from Colombia and a review of these anomalies in bats (Chiroptera). Chiroptera Neotropical 20(2): 1271-1279.

LUCATI, F. \& LÓPEZ-BAUCELLS, A. (2017). Chromatic disorders in bats: a review of pigmentation anomalies and the misuse of terms to describe them. Mammal Review 47(2): 112-123. https://doi.org/10.1111/mam.12083

MITCHELL, H.A. \& SMITH, C.D. (1966). Anomalous Tails in Tadarida brasiliensis. Journal of Mammalogy 47(1): 148149. https://doi.org/10.2307/1378101

NORBERG, U.M. \& RAYNER, J.M.V. (1987). Ecological morphology and flight in bats (Mammalia; Chiroptera): wing adaptations, flight performance, foraging strategy and echolocation. Philosophical Transactions of the Royal Society 316(1179): 335-427. https://doi.org/10.1098/ rstb. 1987.0030

NORBERG, U. M. (1972). Functional osteology and myology of the wing of the dog-faced bat Rousettus aegyptiacus (É. Geoffroy) (Mammalia, Chiroptera). Zeitschrift für Morphologie der Tiere 73(1): 1-44.

PAPADIMITRIOU, H. M., SWARTZ, S. M. \& KUNZ, T. H. (1996). Ontogenetic and anatomic variation in mineralization of the wing skeleton of the Mexican free-tailed bat, Tadarida brasiliensis. Journal of Zoolgy 240(3): 411-426. https://doi.org/10.1111/j.1469-7998.1996.tb05295.x

PEKINS, C.E. (2009). Polydactyly in the Cave Myotis (Myotis velifer) in North-central Texas. The Southwestern Naturalist 54(2): 222-225. https://doi.org/10.1894/CLG13.1

PHILLIPS, C.J. \& JONES, JR. J.K. (1970). Dental abnormalities in North American bats. II. Possible endogenous factors in dental caries in Phyllostomus hastatus. The University of Kansas Science Bulletin 48(20): 791-799. 
RAMÍREZ-PULIDO, J. \& MÜDESPACHER, C. (1987). Formulas dentarias anormales en algunos murciélagos mexicanos. Acta zoológica mexicana 23: 1-54.

SEARS, K., BEHRINGER, R., RASWEILER, J. \& NISWANDER, L. (2006). Development of bat flight: Morphologic and molecular evolution of bat wing digits. Proceedings of the National Academy of Sciences 103(17): 6581-6586. https://doi.org/10.1073/pnas.0509716103

SWARTZ, S. M. \& MIDDLETON, K. M. (2008). Biomechanics of the bat limb skeleton: scaling, material properties and mechanics. Cells Tissues Organs 187(1): 59-84. https:// doi.org/10.1159/000109964

TÖRNE, O. (1913). Über das knorpelige Accessorium der Vespertilionidenhand. In: Gegenbaurs Morphologisches Jahrbuch. Verlag Von Wilhelm Engelmann, Leipzig, Germany. 431-440 pp.
VOIGT, C. (2013). Bat flight with bad wings: is flight metabolism affected by damaged wings? The Journal of Experimental Biology 216: 1516-121. https://doi. org/10.1242/jeb.079509

WANG, Z., DONG, D., RU, B., YOUNG, R., HAN, N., GUO, T. \& ZHANG, S. (2010). Digital gene expression tag profiling of bat digits provides robust candidates contributing to wing formation. BMC Genomics 11: 619. https://doi. org/10.1186/1471-2164-11-619 